\title{
El riesgo asociado a la banca comercial y universal venezolana
}

\author{
Soto, Antonio* \\ Valente, María ${ }^{* *}$
}

\section{Resumen}

El presente artículo se centra en analizar desde una perspectiva teórico-práctica el comportamiento del riesgo crediticio, calce de plazos y tasas de interés en el conjunto de la banca comercial y universal venezolana para el trienio 1998-2000, años éstos donde las políticas económicas experimentaron comportamientos de diferente corte. A través de una investigación de tipo descriptivo-observacional, los resultados revelan que este importante segmento del sector financiero presentó una exposición al riesgo de calce de plazos al obtener pasivos conformados por depósitos a corto plazo en relación a la tenencia de activos en préstamos a mediano y largo plazo. Igualmente se concluye, el buen desempeño del entorno económico reduce las posibilidades que el sistema financiero se enfrente al riesgo crediticio, dada la mejor posición financiera de los agentes económicos demandantes de fondos prestables. Por su parte, el riesgo de tasas de interés no estuvo presente en el sistema bancario venezolano durante el periodo de estudio, dada la disposición por parte de las políticas monetarias en tratar de bajar el diferencial entre las tasas de interés activas y pasivas, sin que este diferencial se tornara negativo para este importante sector del sistema financiero venezolano.

Palabras clave: Banca, riesgo, crediticio, calce de plazos, tasas de interés.

\section{Risk Associated with Venezuelan Commercial and Universal Banking}

\section{Abstract}

This article focuses on analyzing, from a theoretical-practical perspective, risk behavior related to credit, adjustment term and interest rates in commercial and universal Venezuelan banking as a whole for the triennium 1998-2000, years in which economic policies experienced behaviors of a

Recibido: 28-05-07. Aceptado: 15-10-07

* Profesor Asociado. Centro de Estadística e Investigación de Operaciones. Facultad de Ciencias Económicas y Sociales. Universidad del Zulia. Maracaibo-Venezuela.

E-mail: ajsoto10@cantv.net.

** Profesora Agregada. Instituto de Investigaciones. Facultad de Ciencias Económicas y Sociales. Universidad del Zulia. Maracaibo-Venezuela. E-mail: marivalente@cantv.net. 
different sort. Using descriptive-observational research, results revealed that this important segment of the financial sector demonstrated an exposure to adjustment term risk by obtaining liabilities consisting of short term deposits related to holding assets in medium and long-term loans. Likewise, conclusions were that good performance of the economic environment reduces the possibilities that the financial system faces credit risk, given the better financial position of the economic agents selling funds that can be loaned. Also, interest rate risk was not present in the Venezuelan banking system during the period under study, given the disposition by monetary policies to try and reduce the differential between active and passive interest rates, without allowing this differential to become negative for this important sector of the Venezuelan financial system.

Key words: Banking, risk, credit, adjustment term, interest rates.

\section{Introducción}

Durante la década de los setenta, Venezuela y en particular el sistema financiero venezolano vivieron un periodo de estabilidad, producto de una inflación tendiente a cero, un signo monetario nacional sumamente estable y un sostenido crecimiento económico. Siendo éste el panorama de la economía venezolana, resultaba tal como afirma Piñango (1998) una extravagancia o una exquisitez referirse al riesgo económico o riesgo financiero, aunque según el mismo autor, el mundo ya conocía este tipo de riesgos.

Por su parte, Faraco y Suprani (1995) afirman que hasta 1975 el sistema bancario venezolano era un sector altamente capitalizado, acostumbrado a intermediar en un ambiente macroeconómico estable, bondadoso, predecible, y asumiendo riesgos que se limitaban a la moralidad o capacidad del lobby gubernamental del deudor, ya que los riesgos normales en los negocios de productos, de mercados, de tecnologías, no existían en una economía cerrada, protegida y rentista.

Sin embargo, la situación de estabilidad y crecimiento macroeconómico que había experimentado Venezuela du- rante el período 1950 a 1980; teniendo su clímax a partir de la oleada de aumentos de los precios petroleros a finales del año 1973 y en el transcurso del año 1974, cambia radicalmente, concibiendo una nueva realidad para la economía venezolana y todo su entorno.

Según Faraco y Suprani (1995), el desplome del mercado petrolero internacional en el año 1983, así como la elevación de las tasas de interés externas, y la negativa de los acreedores extranjeros en renovar el masivo endeudamiento a corto plazo contraído por entes descentralizados del Estado y empresas adscritas al sector privado; provocaron una fuerte recesión económica que obligó al gobierno a cerrar el mercado cambiario, establecer una devaluación, e implantar algunas políticas restrictivas de carácter fiscal y monetario. Dichas medidas originaron un cambio en el marco doctrinario del proceso económico venezolano, el cual ha trascendido de manera significativa sobre el sistema financiero venezolano potenciando los riesgos que dicho sector enfrenta usualmente.

Este mismo autor señala, a pesar de la gravedad de los episodios antes mencionados que produjeron la intervención de tres (3) bancos comerciales y seis 
(6) sociedades financieras en el bienio 1983-1984; dado el peso marginal en términos de la cuota del mercado que estas instituciones poseian y un completo respaldo por parte del ejecutivo, no se ocasionó daños al normal funcionamiento del sistema de pagos ni a la actividad económica general del país. No obstante, este hecho introdujo un nuevo concepto dentro del sistema financiero venezolano como lo es el 〈riesgo〉.

Dentro de este marco, Castellano (2000:a) señala que a partir de 1989 debido a la grave situación económica del país, el gobierno adopta una concepción diferente en la aplicación de políticas económicas, orientándose al crecimiento hacia afuera, y ejecutando una serie de reformas estructurales tendientes a corregir los desequilibrios macroeconómicos.

De allí que en Venezuela se aplican una serie de medidas tales como: reducción de los subsidios, liberalización de los precios, flexibilización de las tasas de interés, así como racionalización y liberación del régimen comercial y aduanero; las cuales según Castellano (2000:a) y Faraco y Suprani (1995) tuvieron un impacto negativo sobre el sector empresarial y financiero, pues estimuló la financiación de proyectos de inversión con niveles de rentabilidad inciertos o precarios, aumentando de esta manera lo que Mishkin (1996) denomina el riesgo moral; lo cual desencadenó la crisis bancaria que vivió Venezuela entre 19941995.

A juicio de García et al. (1998), la crisis antes mencionada constituye la de mayor magnitud como proporción del sistema financiero afectado, medido a tra- vés de sus activos, patrimonio o depósitos del público, y el elevado costo que significó el rescate del mismo, aproximadamente el 20 por ciento del PIB.

Por su parte García et al. (1998), citan a Hausmann y Gavin (1996) quienes aseveran que la crisis que enfrentaron las instituciones financieras en Venezuela en el período 1994-95, tiene en gran medida su origen en la ampliación de la cartera de inversiones relacionadas en proporciones extremadamente altas, reflejando una toma directa de riesgo por parte de los directivos y gerentes bancarios.

En este sentido, García et al. (1998) afirman, las crisis bancarias son procesos complejos, multidimensionales en los cuales se combinan indefectiblemente factores de naturaleza macroeconómica, microeconómica, sectorial; y conjuntamente con éstos, existen elementos gerenciales de importancia significativa; teniendo las instituciones financieras como una de sus características más importantes la gerencia y convivencia del riesgo.

La situación referida anteriormente evidencia la presencia de un sistema financiero que ha sido afectado por su entorno, el cual ha incidido de manera directa en las crisis financieras que ha experimentado el país en los últimos años. En este contexto, se hace necesario describir la evolución que han tenido los diferentes tipos de riesgos que afectan tanto a la Banca Comercial como a la Banca Universal.

La presente investigación es considerada como descriptiva y observacional; siendo clasificada de acuerdo al tipo de diseño como no experimental, longitudinal y documental. La población para el 
presente estudio estuvo representada por los datos de los Balances Consolidados de la Banca Comercial y Universal de Venezuela durante el período 1998-2000 suministrados anualmente a través de los Informes Económicos del Banco Central de Venezuela, y de los balances trimestrales y anuales emitidos por la superintendencia de Bancos.

\section{Consideraciones teóricas}

El sistema bancario garantiza el funcionamiento continuo del sistema de pagos, que es un mecanismo imprescindible dentro del sistema financiero; su carácter de imprescindible tiene soporte en el hecho que sus relaciones económicas se extienden por todos los ámbitos de la economía, y la interrupción de su labor de intermediación supone una distorsión en el mecanismo general de transformación del ahorro en inversión.

En este sentido Pérez y Rodríguez (2001:b) señalan, las entidades financieras en general son especialmente sensibles a variaciones que puedan ocurrir en su entorno. El carácter vulnerable del sistema bancario no sólo obedece a su posición como intermediarios de los agentes económicos que depositan y ofrecen sus ahorros a la banca, y a inversionistas que demandan esos fondos en forma de créditos, sino también a su estructura patrimonial pues gestionan activos menos líquidos y de mayor vencimiento en términos generales, que los pasivos.

De manera análoga Orlandoni (2004) señala, los mecanismos de decisión pertinentes al control de riesgo bancario cada vez se ven más afectados en sus mediciones más importantes debido a la dinámica impuesta por los mercados globales, y su implicación en las políticas financieras de impacto local e internacional. De ahí, la necesidad de diseñar metodologías que permanentemente evalúen las variables explicativas de cualquier género que inciden en los cálculos de los índices de control de riesgo.

Según Hausmann y Gavin (1996) la importancia capital que poseen los bancos la constituye el hecho que estos representan el medio a través del cual funciona el sistema de pagos. Este puede representar externalidades importantes para la economía en su conjunto, pues la incapacidad de un banco en cumplir con sus compromisos podría socavar la capacidad de otros bancos, saludables en otros aspectos, para cumplir con los suyos. Esta cascada potencial de interrupciones en el mecanismo de pago reduce la utilidad de todos los depósitos como forma de pago.

Dentro de este orden de ideas, después de la grave crisis financiera que afectó al sistema bancario venezolano entre 1960-1963 y más recientemente el colapso financiero entre 1994-1995, parece ser un axioma demostrar los efectos devastadores que este tipo de crisis ocasionaron al país. Según Faraco y Suprani (1995), sólo el costo de la crisis de 1994 ascendió a un equivalente de $18 \%$ del PIB, y el financiamiento de su manejo ha incrementado la deuda pública casi $33 \%$. Más adelante los mismos autores afirman que un descalabro de estas proporciones e implicaciones no se había registrado durante el siglo $X X$ en ningún país.

Sin embargo, el debate en torno al efecto que las políticas económicas tienen sobre el riesgo asociado a este tipo 
de instituciones no ha llegado a un consenso, pues según García et al. (1998), son muy diversos los factores de naturaleza macroeconómica, microeconómica, sectorial y gerencial que afectan al sistema bancario venezolano en sus distintos tipos de riesgo.

Los riesgos a los cuales se enfrenta el sistema bancario se han intensificado en las últimas dos décadas debido principalmente a la presencia de las entidades en nuevos mercados, a la volatilidad de los precios y a la aparición de nuevos instrumentos financieros. La gestión de estos riesgos es responsabilidad de las instituciones bancarias las cuales deben desarrollar sistemas precisos de medida y control, que hagan posible el cumplimiento de las estrategias marcadas por la dirección. Paralelamente, la responsabilidad de las autoridades consiste en controlar o limitar la exposición al riesgo imponiendo mecanismos que aseguren la solvencia y la estabilidad de las instituciones financieras.

Por esta razón, a continuación se detallarán desde un punto de vista teóri$\mathrm{co}$, los diferentes tipos de riesgos a los cuales se encuentran sometidos la banca comercial y universal venezolana haciéndolas propensas a sufrir discontinuidades en sus actividades financieras, las cuales coadyuvan a generar crisis que no se producen en otro tipo de industrias.

En este sentido, según el Banco Mundial (1989) y Sinkey (1992), citado por García et al. (1998), existen diversos tipos de riegos a los cuales se encuentra sometido las instituciones financieras entre los cuales señalan: el riesgo de calce de plazos, crediticio, de tasas de interés, entre otros.

\subsection{Riesgo de calce de plazos}

El Banco Mundial (1989) y Sinkey (1992), citado por García et al. (1998), conceptualizan a este riesgo como la asimetría que se genera entre la naturaleza de corto plazo de la mayoría de los depósitos o captaciones del sistema financiero y el perfil de vencimiento de mediano o largo plazo de casi la totalidad de sus colocaciones o inversiones. Este tipo de riesgo no representa ningún problema cuando el volumen de depósitos se renueva o rota simultánea y permanentemente en el sistema financiero. En cambio cuando se produce una disminución en la demanda de depósitos, las instituciones financieras pueden verse sometidas a esta asimetría en la estructura de vencimiento de sus operaciones, y ello puede obligarles a asumir ventas de activos con descuento sustanciales para hacer frente a la demanda de fondos líquidos que exige la cancelación de depósitos.

Para Hausmann y Gavin (1996) en la mayoría de las economías, los bancos efectúan una transformación explícita de los instrumentos vencidos, al asumir pasivos conformados por depósitos a corto plazo para tener activos en préstamos a largo plazo.

Según los autores, este tipo de riesgo se profundiza en América Latina de manera vigorosa, ya que aunque los préstamos se otorgan bajo contratos a corto plazo, en realidad se trata de obligaciones a más largo plazo porque las empresas están acostumbradas a refinanciar los préstamos y utilizan estos recursos para financiar actividades que no pueden ser finiquitadas en forma abrupta 
sin incurrir en costos elevados. Si los préstamos no son refinanciados, las empresas se verán obligadas a acometer medidas que reducen su propia rentabilidad y posiblemente la de sus socios, generando un deterioro en la calidad de los préstamos bancarios.

Por lo tanto, independientemente del vencimiento declarado de su cartera de préstamos, el sistema bancario en América Latina está altamente expuesto al riesgo de calce de plazos originado por una falta de liquidez, ya que en su intento de liquidar rápidamente su cartera, reducirá significativamente el valor de sus activos.

De acuerdo a los planteamientos de García et al. (1998), esta asimetría generada por el vencimiento de plazos entre las captaciones y las inversiones del sistema financiero están provocadas por el alto diferencial o spread entre las tasas de interés activas y pasivas. Para este mismo autor, resulta inverosímil la tesis que señala que dichos diferenciales son un mecanismo de previsión o protección que permiten a las instituciones financieras crear fondos de reserva para protegerse de una eventual materialización del deterioro de la economía producto de una acelerada inflación o movimientos del tipo de cambio no previstos, los cuales afectan la calidad de cartera de créditos e inversiones de las instituciones, y por ende su rentabilidad.

Según la posición de este autor, el diferencial entre las tasas de interés activas y pasivas existente en Venezuela se debe básicamente a ineficiencias propias del sistema financiero las cuales se manifiestan en primer lugar en su estructura de costos, y se refleja en el incremento sostenido de los gastos financieros por captaciones de depósitos y la brecha entre los fondos colocables y efectivamente colocados, los cuales originan altos niveles de liquidez. En consecuencia los fondos efectivamente colocados deben producir un rendimiento mayor, es decir, deben ser invertidos a tasas de interés mayores para compensar el menor volumen de recursos financieramente productivos.

En segundo lugar, los bajos niveles de rendimiento de la cartera de créditos e inversiones de las instituciones financieras; producto de una alta cartera relacionada y en estado de mora, así como, bajos niveles de intermediación financiera, originan un mayor diferencial entre las tasas de interés activas y pasivas.

Dentro de esta perspectiva, estudios realizados por Pérez y Rodríguez (2001a y 2001b) señalan la existencia de múltiples factores que afectan el diferencial de las tasas de interés activas y pasivas en Venezuela, haciéndolo uno de los más elevados y atípicos del mundo.

En este estudio, los autores convienen con los argumentos de García et al. (1998) y Faust et al. (2001), atribuyendo como uno de los factores que incide en el spread financiero en Venezuela la ineficiencia del sector bancario, reflejada en la presencia de elevados gastos de transformación en su estructura de costos, los cuales impulsan al sector bancario a traspasar dichos costos a los consumidores de los servicios bancarios con el objeto de recompensar esos elevados costes.

Según Pérez y Rodríguez (2001a) el segundo factor y el de mayor relevancia que explica el alto spread financiero en Venezuela está referido a la falta de competencia del sector bancario. El pri- 
mer indicio de esta aseveración la constituye el hecho que Venezuela posee una de las tasas de ganancias más elevadas ( $\sin$ importar en que ciclo económico en el cual éste se mida) para un grupo representativo de países latinoamericanos, desarrollados y asiáticos. De acuerdo a estos autores, el margen de ganancia del sector bancario venezolano es un dato importante para pensar en la existencia de barreras a la entrada del sistema bancario que impiden que las rentabilidades se equilibren internacionalmente.

Pruebas econométricas llevadas a cabo por Pérez y Rodríguez (2001a) arrojan como resultado que el $41 \%$ del spread financiero venezolano es atribuible a la explotación del poder de mercado. EI análisis realizado por estos autores se basa en el cálculo de la tasa de interés neta ajustada (TINA), la cual representa un estimador más confiable para el cálculo del spread financiero que enfrentan los buscadores de préstamos y los ahorristas.

De todo lo anterior resulta evidente que, tanto la explotación de mercado como los gastos de transformación son determinantes importantes del spread financiero en Venezuela.

\subsection{Riesgo crediticio}

Según el Banco Mundial (1989) y Sinkey (1992), citado por García et al. (1998), este riesgo está determinado por la eventualidad de que los deudores de los bancos se vean imposibilitados de repagar los préstamos, a la vez que las garantías que respaldan esos créditos se ubiquen en ese momento, por debajo del valor del préstamo concedido.
De manera análoga Castellano (2000) plantea, este tipo de riesgo se le denomina así por la probabilidad de que un prestatario (cliente activo) no devuelva el principal de su préstamo o crédito y no pague los intereses de acuerdo con lo estipulado en el contrato. Dentro de esta perspectiva el autor asevera, esta actividad constituye la principal fuente de ingresos para un banco, pero puede ser a su vez la causa determinante de la quiebra de un instituto financiero dado que un préstamo puede aportar tantos ingresos a la cuenta de resultados, como puede ocasionar serios problemas de liquidez en caso de impago tanto de los intereses devengados como el préstamo otorgado.

Según Mishkin (1996:47) "el factor que lideró la crisis del sistema financiero mejicano fue el deterioro de los estados financieros producto de los préstamos incobrables o irrecuperables".

Así mismo García et al. (1998) sostienen, durante 1958-1959, años previos a la crisis financiera venezolana, muchos de los deudores de préstamos bancarios no pudieron cumplir con sus compromisos, lo cual originó que la cartera demorada y en litigio se incrementara significativamente a partir de 1959 coadyuvando a originar la crisis financiera venezolana del período 1960-63.

\subsection{Riesgo de tasas de interés}

El riesgo de tasa de interés (RTI) es el riesgo de que los cambios en la tasa de interés puedan afectar negativamente a la situación económica de una entidad financiera. De acuerdo al Banco Mundial (1989) y Sinkey (1992), citado por García et al. (1998), los bancos están expuestos 
al RTI cuando la diferencia entre las tasas de interés activas (las que cobran las instituciones financieras por los créditos) y las tasas de interés pasivas (las que pagan dichas instituciones para remunerar los depósitos) se invierten en detrimento de las mencionadas instituciones.

En este sentido García et al. (1998), bosquejan como este tipo de riesgo fue soportado por las instituciones financieras venezolanas a partir de la liberación de las tasas de interés y de la aprobación de la Ley de Protección al Deudor Hipotecario, mediante la cual se mantuvieron las tasas de interés para los deudores de préstamos hipotecarios por debajo de los valores que indicaba el mercado, mientras que estas instituciones bancarias tenían que pagar intereses a sus depositantes a las mismas tasas que el resto del sistema financiero, las cuales eran significativamente más altas.

De igual forma señalan los autores García et al., que para finales de la década de los años setenta la banca hipotecaria se vio sometida a este tipo de riesgo cuando las tasas de interés en Venezuela fueron ajustadas en respuesta a los incrementos que las mismas experimentaron en los mercados financieros internacionales, y el público exigió la cancelación de las cédulas hipotecarias que habían sido emitidas a tasas de interés fijas, muy por debajo de los nuevos niveles de aquel entonces.

Por su parte De Juan (1997) señala, este tipo de riesgo reduce seriamente la lucratividad de las instituciones, lo cual resulta elevadamente alarmante. Mas adelante el mismo autor señala, las tasas de interés pueden oscilar con gran fuerza, en particular en épocas de desregla- mentación, incrementándose en general la remuneración de los depósitos cuando la mayoría o todas las carteras de préstamos se basan en tasas fijas.

\section{Principales políticas económicas implantadas en Venezuela durante el trienio 1998-2000}

La evolución de la actividad del sistema financiero en Venezuela es sin duda alguna sensible a las fluctuaciones macroeconómicas y a la forma específica en que adopte la política fiscal y monetaria. En este sentido, a continuación se presentará el desempeño de las políticas fiscal y monetaria de acuerdo a los informes del BCV en el trienio estudiado.

\subsection{Política monetaria y cambiaria}

La política cambiaria y monetaria para los años 1998-1999 estuvo orientada a su objetivo antiinflacionario. De esta forma, la política monetaria fue claramente restrictiva y la misma se sustentó en las operaciones de mercado Abierto (OMA), así como dos nuevos mecanismos para absorción de liquidez monetaria como lo fueron: las Subastas de Compra con Pacto de Reventa y viceversa (REPOS) y las subastas de recompra y compra de títulos emitidos tanto por el BCV como por el gobierno (BCV, 1998-1999).

Para el año 2000 , la política monetaria estuvo caracterizada por dos períodos claramente diferenciables, en el primer semestre tuvo una orientación expansiva dirigida a eliminar el saldo en circulación de los títulos de estabilización monetaria (TEM) aún en circulación. 
Mientras que el segundo semestre tuvo un corte neutral, limitando el BCV sus intervenciones en el mercado de dinero a operaciones puntuales de asistencia crediticia al sistema bancario, y utilizando a la venta de divisas como principal mecanismo de ajuste del mercado de dinero.

\subsection{Política fiscal}

De acuerdo a los informes del BCV (1998-1999), la política fiscal para los años 1998-1999 se caracterizó por tener un corte restrictivo dado el desfavorable desempeño del mercado petrolero internacional, en el cual incidió negativamente el precio de la canasta de exportación de hidrocarburos del país, de esta forma ocasionó que el ejecutivo decretara modificaciones presupuestarias que incluyeron un recorte de gastos, así como la disposición de medidas a fin de reforzar la caída de los ingresos petroleros a través la aprobación de un Impuesto a las transacciones financieras (Impuesto al Débito Bancario) con una alícuota de 0,5\%,y la sustitución del Impuesto al Consumo Suntuario y Ventas al Mayor por el Impuesto al Valor Agregado, fijándose la alícuota de este último en $15,5 \%$.

En el año 2000, la política fiscal se formuló de corte expansivo, inducido a través de la captación de recursos por vía de la colocación de bonos de mediano y largo plazo como la emisión de Letras del Tesoro. De igual forma, a manera de incentivar la reactivación económica a través de la inversión y el consumo, el ejecutivo adoptó medidas de orden fiscal disminuyendo en un punto porcentual la alícuota aplicada por impuesto al valor agregado (IVA, de $15,5 \%$ a $14,5 \%$ ) y exone- rando de este tributo a las entidades decretadas como puertos libres y zonas francas.

\section{Evolución de riesgo asociado a la banca comercial y universal venezolana}

Como se expuso en líneas anteriores, dada la naturaleza de su actividad, los bancos están sometidos a riesgos estrechamente ligados con la dinámica económica general. En este orden de ideas, a continuación se esbozará la evolución de los diferentes tipos de riesgos a los cuales fue sometida la banca comercial y universal venezolana durante los años 1998-2000. Dicho período es tomado en consideración dado lo diametralmente opuestas que fueron las políticas económicas para ese entonces, lo cual permitirá tener un mejor panorama de la influencia que estas últimas tienen sobre el riesgo bancario.

\subsection{Riesgo de calce de plazos}

El riesgo de calce de plazos conceptualizado anteriormente como la asimetría que se genera entre la naturaleza de corto plazo de la mayoría de los depósitos o captaciones del sistema financiero y el perfil de vencimiento de mediano o largo plazo de casi la totalidad de sus colocaciones o inversiones; constituye a juicio de Demirgüç-Kunt y Detragiache (1998), el determinante principal de las crisis bancarias a nivel mundial.

De igual forma, los mismos autores aseveran que la influencia de este tipo de riesgo radica precisamente en la función de intermediarios financieros por parte de 
la banca, los cuales reciben compromisos (depósitos) que se encuentran colocados a corto plazo, mientras que sus activos generalmente son colocados en periodos de tiempo más prolongados.

Al evaluar el riesgo de calce de plazos que afrontó la banca comercial y universal desde el punto de vista de la oferta de fondos prestables (captaciones del público), se pudo observar como la estructura de los depósitos bancarios, la cual constituye parte importante en el análisis de este tipo de riesgo, mostró la inclinación del público por instrumentos de elevada liquidez y cortos plazos de maduración a lo largo del periodo de estudio, sin que esta actitud sea influida por políticas fiscales y monetarias de corte restrictivo (año 1998 y 1999) o de corte expansivo y/o neutral (año 2000).

Tal situación se evidencia al observar la importante participación que po- seen los depósitos en cuenta corriente $(42,64 \% ; 41,69 \% ; 44,70 \%)$, otras obligaciones a la vista $(4,00 \% ; 4,61 \% ; 3,56 \%)$ y depósitos de ahorro (30,07\%; 29,96\%; $28,88 \%$ ), en el total de captaciones del sistema para los años 1998, 1999 y 2000 respectivamente (Tabla 1); porcentajes estos que representaron en conjunto el $76,71 \% ; 76,26 \%$ y $77,14 \%$ del total de depósitos para el trienio estudiado.

Resulta interesante observar cómo la participación de las referidas cuentas (depósitos en cuentas corrientes, otras obligaciones a la vista y depósitos de ahorro) en el total de captaciones presentó un comportamiento casi constante a lo largo del trienio y especialmente la experimentada en el año 1999, año en el cual alcanzó un porcentaje ligeramente inferior a la del año 1998, ubicándose en $76,26 \%$, a pesar del proceso de contracción de la actividad económica venezola-

\section{Tabla 1}

Banca universal y comercial. Estructura de las captaciones del público (en porcentajes). Período 1997-2000

\begin{tabular}{lcccc}
\hline & 1997 & $\mathbf{1 9 9 8}$ & $\mathbf{1 9 9 9}$ & $\mathbf{2 0 0 0}$ \\
\hline Captaciones del público & 100,00 & 100,00 & 100,00 & 100,00 \\
Depósitos en cuentas corrientes (1) & 49,15 & $\mathbf{4 2 , 6 4}$ & $\mathbf{4 1 , 6 9}$ & $\mathbf{4 4 , 7 0}$ \\
$\quad$ Cuentas corrientes no remuneradas & 34,71 & 28,66 & 27,22 & 28,55 \\
$\quad$ Cuentas corrientes remuneradas & 14,43 & 13,98 & 14,46 & 16,14 \\
Otras obligaciones a la vista (2) & 2,55 & $\mathbf{4 , 0 0}$ & $\mathbf{4 , 6 1}$ & $\mathbf{3 , 5 6}$ \\
Obligaciones por Operaciones de mesa de Dinero & 0,04 & 0,05 & 0,01 & 0,06 \\
Depósitos de ahorro (3) & 33,76 & $\mathbf{3 0 , 0 7}$ & $\mathbf{2 9 , 9 6}$ & $\mathbf{2 8 , 8 8}$ \\
SUB-TOTAL (1+2+3) & 85,46 & $\mathbf{7 6 , 7 1}$ & $\mathbf{7 6 , 2 6}$ & $\mathbf{7 7 , 1 4}$ \\
Depósitos a Plazo & 13,56 & 21,99 & 22,75 & 21,42 \\
Títulos Valores Emitidos por la Institución & 0,01 & 0,02 & 0,10 & 0,22 \\
Captaciones del público Restringidas & 0,79 & 0,76 & 0,89 & 1,16 \\
\hline
\end{tabular}

Fuente: Elaboración propia con base a la información de Sudeban (2002). 
na de $6,1 \%$ en términos reales, lo que evidencia no sólo la actitud del público de mantener una acumulación de recursos con fines netamente transaccionales, sino también el reducido número de alternativas de inversión ofrecidas por las instituciones financieras, y el bajo nivel registrado por la tasa de interés pasiva promedio durante el periodo de estudio (3,5\% en términos reales).

Al evaluar el perfil de vencimiento de demanda de fondos prestables en el componente de colocaciones que la banca comercial y universal venezolana formalizó, se observa cómo la cartera de crédito por plazo de vencimiento (la cual representa parte importante de este segmento del sistema financiero) presentó un comportamiento marcadamente diferente con relación a los depósitos del público, pues mientras estos últimos alcanzaron niveles superiores al $76 \%$ con un vencimiento a muy corto plazo durante el trienio estudiado, la cartera de crédito de más de 91 días alcanzó el 35,44\%; $53,83 \%$ y $50,59 \%$ para el trienio bajo estudio, representando los créditos mayores de 360 días el 21,22\%; 30,97\% y $29,72 \%$ para el mismo período, situación ésta que se agravó para el año 1999, pues los créditos de más de 90 días hasta 180 días presentaron el mayor porcentaje de vencimiento y en litigio alcanzando el 7,69\% (Tabla 2).

Es importante señalar que para el año 1998 , la cartera de créditos por plazo de vencimiento registró un comportamiento atípico, ya que ubicó a los créditos hasta treinta días en su mayor porcentaje de participación con $44,83 \%$ (Tabla 2). Dicha situación puede ser atribuida al incremento de expectativas negativas por parte de los agentes económicos, producto del deterioro de los precios de los hidrocarburos y su influencia en las cuentas fiscales y externas de la nación, lo cual coadyuvó a una mayor tensión financiera de los deudores y los obligó a contraer créditos a plazos menores. De allí que este tipo de créditos presentara el menor porcentaje de créditos vencidos del año 1998.

Por otra parte para el año 1999, los créditos mayores a 360 días constituyeron el segundo mayor porcentaje de créditos en condición de vencidos y en litigio alcanzando el $5,33 \%$ y $0,83 \%$ respectivamente (Tabla 2), situación que incrementa los riesgos a los cuales se enfrentó el sistema financiero, pues no sólo presentó asimetrías en la estructura de vencimiento de sus operaciones, sino que dentro de las mismas, los créditos presentaron una considerable participación en relación a su vencimiento y condición de litigio.

De manera análoga para el año 2000 , el perfil de vencimiento de las colocaciones de la banca comercial y universal venezolana presentó un comportamiento similar al de los años 1999 y 1998 , al ubicarse la participación de las cuentas más líquidas del total de las captaciones en $56,07 \%$; mientras que la cartera de créditos por plazo de vencimiento de más de 91 días ( 91 días a 180 días + 181 días a 360 días + mayores de 360 días) alcanzó el $50,59 \%$ en conjunto, representando los créditos mayores de 360 días el $29,72 \%$ del total de los referidos créditos, situación esta que continúa con el deterioro del calce de plazos si se toma en cuenta el hecho que los créditos de más de 90 días hasta 180 días presentaron el mayor porcentaje de vencimiento y en liti- 
Tabla 2

Banca universal y comercial. Cartera de crédito por plazo de vencimiento (en porcentajes). Período 1998-2000

\begin{tabular}{|c|c|c|c|}
\hline Captaciones del público & 1998 & 1999 & 2000 \\
\hline Hasta 30 dias (1) & 44,83 & 31,09 & 30,64 \\
\hline Vigentes & 96,64 & 93,23 & 94,29 \\
\hline Reestructurados & 0,38 & 1,17 & 1,13 \\
\hline Vencidos & 2,72 & 5,04 & 3,79 \\
\hline en litigio & 0,25 & 0,56 & 0,79 \\
\hline 31 dias a 60 dias (2) & 12,46 & 11,41 & 13,52 \\
\hline Vigentes & 96,80 & 93,12 & 97,15 \\
\hline Reestructurados & 0,25 & 0,89 & 0,50 \\
\hline Vencidos & 2,92 & 5,84 & 2,07 \\
\hline en litigio & 0,04 & 0,15 & 0,27 \\
\hline 61 dias a 90 días (3) & 10,94 & 11,57 & 11,91 \\
\hline Vigentes & 93,68 & 94,66 & 94,88 \\
\hline Reestructurados & 2,25 & 1,43 & 0,70 \\
\hline Vencidos & 3,91 & 3,66 & 3,69 \\
\hline en litigio & 0,16 & 0,25 & 0,73 \\
\hline Sub-total $(1+2+3)$ & 68,23 & 54,07 & 56,07 \\
\hline 91 días a 180 días (4) & 7,98 & 9,11 & 10,21 \\
\hline Vigentes & 86,73 & 92,02 & 92,78 \\
\hline Reestructurados & 1,32 & 0,29 & 0,19 \\
\hline Vencidos & 11,36 & 7,03 & 5,97 \\
\hline en litigio & 0,59 & 0,66 & 1,06 \\
\hline 181 días a 360 días (5) & 6,24 & 13,75 & 10,66 \\
\hline Vigentes & 89,63 & 95,03 & 93,40 \\
\hline Reestructurados & 1,45 & 0,41 & 1,85 \\
\hline Vencidos & 8,06 & 3,46 & 3,71 \\
\hline en litigio & 0,87 & 1,10 & 1,04 \\
\hline Mayores de 360 días (6) & 21,22 & 30,97 & 29,72 \\
\hline Vigentes & 94,39 & 90,84 & 91,96 \\
\hline Reestructurados & 1,59 & 2,99 & 2,88 \\
\hline Vencidos & 3,59 & 5,33 & 4,13 \\
\hline en litigio & 0,43 & 0,83 & 1,03 \\
\hline Sub total $(4+5+6)$ & 35,44 & 53,83 & 50,59 \\
\hline RENDIMIENTOS POR COBRAR & & $-7,89$ & $-6,65$ \\
\hline PROVISIÓN & $-6,79$ & & \\
\hline TOTAL & 100,00 & 100,00 & 100,00 \\
\hline
\end{tabular}

Fuente: Elaboración propia con base a la información de Sudeban (2002). 
gio alcanzando el $5,97 \%$ y $1,06 \%$ respectivamente (Tabla 2).

De igual forma, los créditos mayores a 360 días constituyeron el segundo mayor porcentaje de créditos en condición de vencidos y en litigio alcanzando el $4,13 \%$ y $1,03 \%$ respectivamente, situación que como se señaló anteriormente incrementa los riesgos a los cuales se enfrentó este importante segmento del sistema financiero.

Al evaluar el segundo componente de demanda de fondos prestables, como lo son las inversiones, la asimetría del calce de plazos es aún más crítica, pues a juicio de Castellano (2000) para el año 1998 del total de inversiones temporales y permanentes, los títulos valores emitidos o avalados por la nación en cada una de las inversiones señaladas alcanzaron el $76,82 \%$ y $40,94 \%$ respectivamente. Por su parte, del total de las inversiones en títulos valores llevadas a cabo durante los años 1999-2000, las inversiones mantenidas hasta su vencimiento alcanzaron el $45,03 \%$ y $31,67 \%$ del total de las inversiones en títulos valores, porcentajes estos elevados ya que la banca no podría hacer uso de ese tipo de inversiones para afrontar una eventual disminución de la demanda de depósitos.

Lo anteriormente señalado permite concluir que el sistema financiero venezolano presenta una transformación explícita de instrumentos vencidos, al obtener pasivos conformados por depósitos a corto plazo en relación a la tenencia de activos en préstamos a mediano y largo plazo; evidenciando la existencia de una elevada exposición a riesgo de calce de plazos.

\subsection{Riesgo crediticio}

Como se expresó en líneas anteriores, García et al. (1998) citando al Banco Mundial (1989) y Sinkey (1992), definen al riesgo crediticio como la eventualidad de que los prestatarios o deudores de los bancos se vean imposibilitados de cumplir o repagar sus obligaciones (préstamos) ante el banco, a la vez que las garantías que respaldan esos créditos se ubiquen en ese momento, por debajo del valor del préstamo concedido, constituyéndose este tipo de riesgo en el más común dentro del sistema bancario. Según Mishkin (1996), este tipo de riesgo fue el principal detonante para que se produjera la crisis del sistema financiero mejicano.

En este sentido, para evaluar la manera como fue el desenvolvimiento del riesgo crediticio, el mismo se llevó a cabo a través de ciertas cuentas que componen el activo improductivo, entre las cuales se pueden citar: los créditos vencidos, créditos en litigio, interés y las comisiones por cobrar. La razón que fundamenta el estudio de las referidas cuentas lo constituye la forma como éstas reflejan la posición de los prestatarios de imposibilidad de cumplimiento de los préstamos ante el banco, de manera que al evaluar cada una de ellas se podrá establecer la existencia del riesgo de crédito dentro del sistema bancario venezolano.

Durante el bienio 1998-99, dado el pobre desempeño de la economía y la carencia por parte del ejecutivo nacional en reactivar el gasto público, la participación de los créditos vencidos en el total del Activo de la banca comercial y universal in- 
crementó su participación al pasar de $1,98 \%$ en 1998 a $2,39 \%$ en 1999 (Tabla 3).

Comportamiento similar fue el caracterizado por los créditos en litigio los cuales aumentaron su participación en el total del activo al pasar de 0,15\% en 1998 a 0,30\% en 1999 (Tabla 3). Al evaluar los porcentajes de participación de los créditos vencidos y en litigio como porcentaje de los créditos otorgados por la banca comercial y universal, los resultados reflejan un mayor deterioro, alcanzando el $6,11 \%$ para el año 1999 , representando un incremento de 0,99 puntos porcentuales con relación al año 1998, lo que evidencia el efecto contractivo de la economía durante el año 1999 y los constantes atrasos en la ejecución presupuestaria debido a las dificultades de acceso al financiamiento externo y al aplazamiento de las privatizaciones.

Durante el año 2000, al hacer un análisis de este tipo de riesgo se observa cómo la reactivación del gasto interno a través de la política fiscal y monetaria (primer semestre) de corte expansivo sin que estas ejercieran presiones inflacionarias sobre la economía, propició una disminución de participación de los créditos vencidos en el total de activo de la banca comercial y universal para el año 2000 , ubicándolo en 1,73\%; permitiendo una disminución de 0,66 puntos en relación al año 1999 (Tabla 3), año éste signado por una caída del Producto Interno Bruto (PIB) y contracción del gasto público.

Resulta interesante la manera cómo los créditos en litigio aumentaron su participación en el total del activo al pasar de $0,30 \%$ a $0,37 \%$ (Tabla 3). Dicho comportamiento obedeció al proceso de contracción de la economía acarreado durante los dos años anteriores, siendo los sectores manufactureros y transporte, almacenes y comunicaciones los únicos que presentaron una disminución en su cartera de créditos en litigio.

Al evaluar los porcentajes de participación de los créditos vencidos y en liti-

\section{Tabla 3}

Banca universal y comercial. Estructura de la cartera de créditos con relación al total del activo (en porcentajes). Periodo 1997-2000

\begin{tabular}{lrrrr}
\hline & 1997 & $\mathbf{1 9 9 8}$ & $\mathbf{1 9 9 9}$ & $\mathbf{2 0 0 0}$ \\
\hline Cartera de créditos & 50,30 & 47,40 & 43,99 & 41,93 \\
Créditos vigentes & 50,13 & 46,53 & 44,05 & 41,96 \\
Créditos reestructurados & 0,30 & 0,47 & 0,72 & 0,66 \\
Créditos vencidos & 0,96 & $\mathbf{1 , 9 8}$ & $\mathbf{2 , 3 9}$ & $\mathbf{1 , 7 3}$ \\
Créditos en litigio & 0,16 & $\mathbf{0 , 1 5}$ & $\mathbf{0 , 3 0}$ & $\mathbf{0 , 3 7}$ \\
Cánones de arrendamiento financiero & 0,01 & & & \\
devengados y no cobrados & & & & \\
Rendimientos por cobrar por cartera de créditos & 0,63 & 1,48 & & $-2,79$ \\
(Provisión para cartera) & $-1,89$ & $-3,22$ & $-3,47$ & \\
\hline
\end{tabular}

Fuente: Elaboración propia con base a la información de Sudeban (2002). 
gio como porcentaje de los créditos otorgados por la banca comercial y universal para el año 2000, los resultados se presentan alentadores al ubicarse los mismos en $5,01 \%$, presentando una mejora de 1,11 puntos en relación al año inmediato anterior cuando se ubicaron en $6,11 \%$; demostrándose así que el efecto de políticas económicas de corte expansivo propiciadas por un mayor volumen de ingresos fiscales constituyen fuentes primordiales de control del riesgo crediticio en el sistema bancario.

Todo lo anterior permite suponer que el riesgo crediticio durante el año 2000 conservó una tendencia a la baja, sustentado en la mejor posición financiera de los agentes económicos demandantes de fondos prestables.

\subsection{Riesgo de tasas de interés}

A juicio de García et al. (1998), este tipo de riesgo surge cuando la diferencia entre las tasas de interés activas y las tasa de interés pasivas se alteran en detrimento de las instituciones bancarias; situación ésta definida como grave para De Juan (1997), pues reduce peligrosamente la rentabilidad de las instituciones financieras exponiéndolas al riesgo moral.

Con la finalidad de poder identificar la forma como las políticas monetarias afectaron a las tasas de interés y a su vez al riesgo que involucra las mismas, la evolución de las tasas de interés atendieron a lo que se señala como los mecanismos de transmisión de la política monetaria desde la perspectiva keynesiana, en el sentido que una tendencia expansiva de la política monetaria conllevará a una caí- da de la tasa de interés real, lo cual disminuirá el costo del capital originando un incremento en los gastos de inversión y por consecuencia un aumento en la demanda agregada.

En este sentido, durante el año 1998 y dada la característica restrictiva de la política monetaria del Banco Central de Venezuela (BCV), se llevaron a cabo Operaciones de Mercado Abierto (OMA) por medio de la colocación de certificados de depósitos y a partir del mes de abril, de los Títulos de Estabilización Monetaria (TEM), los cuales reflejaron un rendimiento de $43,2 \%$ cuya finalidad era extender el efecto contractivo de dichas operaciones BCV (1998).

De igual forma, se incrementó la tasa de interés que cobra el ente emisor por sus operaciones de descuento, redescuento y anticipo, al pasar de un nivel de 45 puntos porcentuales a 60 puntos porcentuales. Esto indujo a un incremento de las tasas de interés tanto pasivas como activas llegando a alcanzar el máximo histórico de la serie analizada, al ubicarse en el mes de septiembre en $76,2 \%$ la tasa activa y $57,1 \%$ la tasa pasiva (Tabla 4); ubicando el spread nominal en 19,1 puntos porcentuales y el real en 23,5 puntos (Tabla 5), situación esta que se aleja de manera categórica al riesgo de tasas de interés.

Para el año 1999, el seguimiento de una política monetaria por parte del BCV que propició una baja sostenida de los Títulos de Estabilización Macroeconómica (TEM), coadyuvó a la mayor baja de las tasas de interés en sus valores nominales y reales del trienio estudiado; dicho esto, la tasa de interés de las operaciones activas del sistema de la banca co- 


\section{Tabla 4}

Seis bancos comerciales y universales con mayor volumen de depósitos. Tasas de interés promedio (en porcentajes).

Período 1998-2000

\begin{tabular}{|c|c|c|c|c|}
\hline & \multicolumn{2}{|c|}{ Préstamos y descuentos ${ }^{1 /}$} & \multicolumn{2}{|c|}{ Depósitos a Plazo Fijo ${ }^{2 \prime}$} \\
\hline & Nominal & Real & Nominal & Real \\
\hline Promedio anual (1998) & 51,4 & 26,2 & 37,6 & 11,3 \\
\hline Enero & 33,6 & 8,3 & 18,6 & $-5,9$ \\
\hline Febrero & 39,2 & 13,8 & 27,0 & 1,7 \\
\hline Marzo & 40,6 & 15,2 & 28,2 & 2,8 \\
\hline Abril & 40,9 & 14,6 & 28,6 & 2,4 \\
\hline Mayo & 45,2 & 15,5 & 35,7 & 6,0 \\
\hline Junio & 47,1 & 19,3 & 36,1 & 8,0 \\
\hline Julio & 62,6 & 35,3 & 46,8 & 17,7 \\
\hline Agosto & 65,0 & 38,1 & 47,8 & 18,8 \\
\hline Septiembre & 76,2 & 55,4 & 57,1 & 31,9 \\
\hline Octubre & 60,2 & 37,3 & 45,8 & 20,8 \\
\hline Noviembre & 54,1 & 30,1 & 40,8 & 15,5 \\
\hline Diciembre & 52,1 & 30,9 & 38,8 & 16,0 \\
\hline Promedio anual (1999) & 31,3 & 11,2 & 21,0 & 1,0 \\
\hline Enero & 39,0 & 15,8 & 34,5 & 11,1 \\
\hline Febrero & 39,7 & 18,0 & 34,4 & 12,4 \\
\hline Marzo & 34,4 & 14,4 & 26,7 & 6,5 \\
\hline Abril & 30,3 & 10,5 & 24,2 & 4,4 \\
\hline Mayo & 28,2 & 7,5 & 21,4 & 0,8 \\
\hline Junio & 31,0 & 11,4 & 18,6 & $-0,9$ \\
\hline Julio & 30,2 & 9,6 & 15,8 & $-4,4$ \\
\hline Agosto & 29,3 & 8,5 & 12,7 & $-7,3$ \\
\hline Septiembre & 28,7 & 9,9 & 13,5 & $-4,9$ \\
\hline Octubre & 29,0 & 9,8 & 14,5 & $-4,3$ \\
\hline Noviembre & 28,1 & 9,4 & 17,8 & $-0,9$ \\
\hline Diciembre & 28,1 & 9,7 & 17,3 & $-1,1$ \\
\hline Promedio anual (2000) & 24,5 & 7,7 & 14,9 & $-1,8$ \\
\hline Enero & 29,2 & 8,6 & 18,4 & $-1,9$ \\
\hline Febrero & 29,0 & 11,2 & 15,2 & $-2,4$ \\
\hline Marzo & 25,1 & 6,3 & 14,4 & $-4,1$ \\
\hline Abril & 26,0 & 6,1 & 15,0 & $-4,4$ \\
\hline Mayo & 23,1 & 2,8 & 15,0 & $-4,8$ \\
\hline Junio & 26,2 & 6,2 & 16,4 & $-3,2$ \\
\hline Julio & 23,4 & 5,4 & 14,2 & $-3,5$ \\
\hline Agosto & 23,7 & 7,2 & 14,9 & $-1,4$ \\
\hline Septiembre & 23,7 & 9,9 & 14,0 & 0,2 \\
\hline Octubre & 21,1 & 7,7 & 13,8 & 0,4 \\
\hline Noviembre & 21,7 & 10,0 & 13,7 & 1,9 \\
\hline Diciembre & 22,0 & 10,4 & 13,5 & 1,8 \\
\hline Desviación estándar & 13,99 & 9,83 & 11,75 & 6,90 \\
\hline
\end{tabular}




\section{Tabla 5}

Seis bancos comerciales y universales con mayor volumen de depósitos. Spread nominal y real (en porcentajes). Período 1998-2000

\begin{tabular}{|c|c|c|}
\hline Meses & Spread nominal & Spread real \\
\hline Enero & 15 & 14,2 \\
\hline Febrero & 12,2 & 12,1 \\
\hline Marzo & 12,4 & 12,4 \\
\hline Abril & 12,3 & 12,2 \\
\hline Mayo & 9,5 & 9,5 \\
\hline Junio & 11 & 11,3 \\
\hline Julio & 15,8 & 17,6 \\
\hline Agosto & 17,2 & 19,3 \\
\hline Septiembre & 19,1 & 23,5 \\
\hline Octubre & 14,4 & 16,5 \\
\hline Noviembre & 13,3 & 14,6 \\
\hline Diciembre & 13,3 & 14,9 \\
\hline Promedio anual (1998) & 13,79 & 14,8 \\
\hline Enero & 4,5 & 4,6 \\
\hline Febrero & 5,3 & 5,6 \\
\hline Marzo & 7,7 & 7,9 \\
\hline Abril & 6,0 & 6,1 \\
\hline Mayo & 6,8 & 6,7 \\
\hline Junio & 12,4 & 12,3 \\
\hline Julio & 14,4 & 13,9 \\
\hline Agosto & 16,6 & 15,9 \\
\hline Septiembre & 15,2 & 14,8 \\
\hline Octubre & 14,5 & 14,1 \\
\hline Noviembre & 10,4 & 10,2 \\
\hline Diciembre & 10,9 & 10,7 \\
\hline Promedio anual (1999) & 10,39 & 10,2 \\
\hline Enero & 10,8 & 10,5 \\
\hline Febrero & 13,7 & 13,6 \\
\hline Marzo & 10,7 & 10,3 \\
\hline Abril & 11,0 & 10,5 \\
\hline Mayo & 8,0 & 7,6 \\
\hline Junio & 9,8 & 9,4 \\
\hline Julio & 9,2 & 8,9 \\
\hline Agosto & 8,8 & 8,7 \\
\hline Septiembre & 9,7 & 9,7 \\
\hline Octubre & 7,3 & 7,3 \\
\hline Noviembre & 8,0 & 8,1 \\
\hline Diciembre & 8,4 & 8,6 \\
\hline Promedio anual (2000) & 9,63 & 9,4 \\
\hline
\end{tabular}

Fuente: Elaboración propia con base a los datos de BCV (2002). 
mercial y universal decreció 20,1 puntos porcentuales con respecto al año 1998, para situarse al finalizar el año en 31,3\%; mientras que la tasa de interés de los depósitos a plazo fijo a 90 días se ubicó en un nivel de $21,0 \%$, lo cual significó una reducción de 16,6 puntos porcentuales con respecto al promedio alcanzado el año 1998 (Tabla 4).

Por otro lado, la tasa real activa se ubicó en promedio en $11,2 \%$ lo que representó una caída de 15 puntos porcentuales con relación al año 1998 (Tabla 4). Cabe resaltar que a pesar de tal caída, la misma fue insuficiente ya que este nivel de tasa real activa era relativamente alto, lo que limitó su impacto positivo sobre las decisiones de consumo e inversión de la economía.

Por su parte, la tasa real pasiva se ubicó en $1 \%$ disminuyendo 10,3 puntos porcentuales en relación al año anterior. Es de resaltar que a partir del mes de junio las referidas tasas se tornaron negativas, lo que contribuyó a que los agentes económicos buscasen nuevas alternativas de inversión y ejercieran presiones sobre la divisa norteamericana.

Para el año 2000, específicamente durante el primer semestre del año, la actuación de la política monetaria estuvo visiblemente comprometida con la expansión de la masa monetaria, al eliminar el saldo en circulación de los títulos de estabilización monetaria (TEM), lo cual permitió la caída en promedio de la tasa de interés real en una forma automática.

En este sentido, el efecto expansivo de la política monetaria llevada a cabo por el gobierno central, y sustentada en la gran disponibilidad de ingresos petrole- ros explicado en líneas anteriores; permitió la recuperación de la demanda agregada en un contexto de disminución de la inflación producto de los bajos niveles de utilización de los recursos productivos acumulados durante la contracción económica de años anteriores, así como la reasignación del gasto hacia los bienes producidos en el exterior.

La mencionada actuación de la política monetaria contribuyó de manera específica a la disminución de las tasas de interés durante el año 2000, particularmente las tasas activas de los seis (6) principales bancos comerciales y universales, las cuales se ubicaron en $24,5 \%$, registrando una contracción de 6,8 puntos porcentuales con relación al año anterior donde se ubicaron en 31,3\% (Tabla 4). De manera análoga, las tasas pasivas se situaron en $14,9 \%$, registrando una contracción de $6,10 \%$ con relación al año 1999 , año en el cual se ubicaron en $21 \%$ (Tabla 4); situándose para el año 2000 el spread financiero en $9,63 \%$ (Tabla 5), porcentaje éste inferior al $10,39 \%$ registrado en el año 1999.

En relación a las tasas de interés reales tanto activas como pasivas, las mismas continuaron una tendencia hacia la baja, ubicándose en $7,7 \%$ y $-1,8 \%$ respectivamente, porcentajes estos inferiores a los alcanzados en 1999, año en el cual se ubicaron las referidas tasas en $11,20 \%$ y $1 \%$ (Tabla 4 ).

Es pertinente mencionar que dicha baja constituyó una caída de 3,5 puntos para la tasa real activa y 2,8 puntos porcentuales para la tasa real pasiva, lo cual creó una situación de garantía para la banca comercial y universal en relación al 
riesgo de tasas de interés, pues las remuneraciones de los depósitos a 90 días los cuales constituían para la época el $47,59 \%$ del total de las captaciones del público, desmejoraron de manera significativa y se tornaron negativas, situación que se venía presentando desde junio de 1999 y culminó en agosto de 2000, lo que originó que durante ese período la tasa real pasiva se ubicara en $(-3,3 \%)$.

De acuerdo a lo explicado anteriormente, la inexistencia del riesgo de tasas de interés en la porción más importante del segmento del sistema financiero venezolano se constató tanto en la poca variabilidad de la oscilación de las tasas de interés (lo que representó una desviación estándar de $13,99 \%$ y $11,75 \%$ puntos porcentuales tanto de la tasa activa como la pasiva para el trienio 1998-2000), como en la posición de las tasas de interés que las instituciones bancarias remuneran a los depositantes a distintos plazos, las cuales se ubicaron siempre por debajo de las tasas que las instituciones bancarias cobraron por los diferentes tipos de servicios de crédito a los usuarios de los mismos, ubicándose el spread financiero en 13,$79 ; 10,39 \%$ y $9,63 \%$ para los años 1998,1999 y 2000 (Tabla 5).

Es pertinente mencionar que dada la conceptualización aportada por el Banco Mundial (1989) y Sinkey (1992), citado por García et al. (1998), el riesgo de tasas de interés sólo puede ser provocado cuando las tasas de interés son ajustadas de manera unilateral por parte del Ejecutivo.

Al realizar un análisis de este tipo de riesgo en Venezuela, García et al. (1998) señalan, el mismo fue soportado por las instituciones financieras venezo- lanas a partir de la liberación de las tasas de interés y de la aprobación de la Ley de Protección al Deudor Hipotecario, mediante la cual se mantuvieron las tasas de interés para los deudores de préstamos hipotecarios por debajo de los valores que indicaba el mercado, mientras que estas instituciones bancarias tenían que pagar intereses a sus depositantes a las mismas tasas que el resto del sistema financiero, las cuales eran significativamente más altas; originando así un deterioro en la rentabilidad del sistema.

\section{Conclusiones}

El sistema financiero venezolano presenta una transformación explícita de instrumentos vencidos, al obtener pasivos conformados por depósitos a corto plazo en relación a la tenencia de activos en préstamos a mediano y largo plazo; evidenciando la existencia de una elevada exposición a riesgo de calce de plazos. Dicha aseveración tiene su soporte en la actitud del público de mantener una acumulación de recursos con fines netamente transaccionales, soportado en gran parte por el reducido número de alternativas de inversión ofrecidas por las instituciones financieras, así como el bajo nivel registrado por la tasa de interés pasiva durante el periodo de estudio $(3,5 \%$ en términos reales), y las grandes expectativas de devaluación.

La oferta de fondos prestables (captaciones del público) mostró la inclinación del público por instrumentos de elevada liquidez y cortos plazos de maduración a lo largo del período de estudio, sin que esta actitud estuviese influida por políticas fiscales y monetarias de corte 
restrictivo (año 1998) o de corte expansivo y/o neutral (años 1999-2000), lo que se evidencia al observar la importante participación que obtuvieron los depósitos en cuenta corriente $(42,64 \% ; 41,69 \%$; $44,70 \%)$, otras obligaciones a la vista $(4,00 \% ; 4,61 \% ; 3,56 \%)$ y depósitos de ahorro (30,07\%; 29,96\%; $28,88 \%)$ en el total de captaciones del sistema para los años 1998,1999 y 2000 respectivamente; porcentajes estos que representaron en conjunto el $76,71 \% ; 76,26 \%$ y $77,14 \%$ dentro del total de depósitos para el trienio estudiado.

El riesgo crediticio se potenció de manera considerable durante el bienio 1998-99, dado el pobre desempeño de la economía y la carencia por parte del ejecutivo nacional en reactivar el gasto público.

La participación de los créditos vencidos en el total del Activo de la banca comercial y universal incrementó su participación al pasar de 1,98\% en 1998 a $2,39 \%$ en 1999. De igual forma, los créditos en litigio aumentaron su participación en el total del activo al pasar de $0,15 \%$ en 1998 a $0,30 \%$ en 1999 , lo que sin duda alguna, aunado al proceso recesivo de la economía durante el referido período menoscabó la capacidad de pagos de los agentes económicos. Para el año 2000, dado el buen desempeño de la economía se observó una disminución de participación de los créditos vencidos en el total de activo de la banca comercial y universal, lo que permite concluir que el buen desempeño del entorno económico reduce las posibilidades que el sistema financiero padezca este tipo de riesgos dada la mejor posición financiera de los agentes económicos demandantes de fondos prestables.

El riesgo de tasas de interés no estuvo presente en el sistema bancario venezolano durante el período de estudio, ya que éste sólo puede ser provocado cuando las tasas de interés son ajustadas de manera unilateral por parte del Ejecutivo Nacional. En este sentido, se evidenció la disposición por parte de las políticas monetarias en tratar de bajar el diferencial entre las tasas activas y pasivas, pero en ningún momento este diferencial se tornó negativo para la Banca.

\section{Referencias Bibliográficas}

Banco Central de Venezuela. (1998 al 2000). Informes Económicos.

Castellano Alberto (2000). "Análisis del Riesgo Asociado a la Banca Universal Venezolana. Período 1996-1998. Trabajo de Grado, Maestría en Gerencia de Empresa, Mención Gerencia Financiera. 1-76.

De Juan, Aristóbulo (1997). "Aspectos microeconómicos de las crisis bancarias". Revista BCV. volumen XI, № 1. 6391.

Demirgüç-Kunt, A. and Detragiache E. (1998), "The Determinants of Banking Crises in Developing Countries and Developed Countries". IMF Staff Papers Vol.45, №1. 1-29.

Faraco, F., Suprani R. (13/02/95). La debacle del sector Bancario. Marco conceptual contra la crisis. Especial/Economía Hoy.

Faust, A; Zambrano L; Vera, L. (2001). Evolución y determinantes del spread financiero en Venezuela. Revista BCV, Vol. XV, № 2 .

García Gustavo, Rodríguez Rafael y Salvato Silvia (1998). Colecciones de la Cri- 
sis Bancaria de Venezuela. Ediciones IESA. Caracas, Venezuela.

Hausmann R. y Gavin M. (1996). Orígenes de las crisis Bancarias en el Contexto macroeconómico. Revista del BCV. X. 31-78.

Mishkin F. (1996). "Understanding Financial Crises: A Developing Country Perspective" in Michael Bruno and Boris Pleskovic, eds., Annual World Bank Conference on Development Economics 1996 (World Bank: Washington D.C. 1996): 29-62.

Orlandoni, Giampaolo (2004). Análisis integral de riesgo en la Banca Comer- cial y Entidades Financieras. Instituto de Investigaciones Económicas y Sociales-Universidad de los Andes ULA.

Pérez F. y Rodríguez F. (2001a). ¿Por qué Venezuela tiene diferenciales de tasas tan altos? Informe de la Oficina de Asesoría Económica y Financiera de la Asamblea Nacional. Marzo 2001. Caracas: OAEFAN. pp 76.

Pérez F. y Rodríguez F. (2001 b). El Balance de la Banca. Debates IESA. Volumen VII. Número 1. Julio-Septiembre 2001. pp 96.

Piñango R. (1997). Riesgo financiero. Debates IESA. Vol 2, Nro. 3. Enero-Marzo. 